\title{
Experimental Research on Foamed Mixture Lightweight Soil Mixed with Fly-Ash and Quicklime as Backfill Material behind Abutments of Expressway Bridge
}

\author{
Xin Liu, ${ }^{1}$ Ke Sheng, ${ }^{2}$ Zhi-long Li, ${ }^{2}$ Liang-qin Gan, ${ }^{2}$ Hao Shan, ${ }^{2}$ and Bao-ning Hong ${ }^{2}$ \\ ${ }^{1}$ Key Laboratory of Ministry of Education for Geomechanics and Embankment Engineering, Jiangsu Research Center for \\ Geotechnical Engineering Technology, Institute of Tunnel and Underground Engineering, Hohai University, Nanjing, China \\ ${ }^{2}$ Key Laboratory of Ministry of Education for Geomechanics and Embankment Engineering, Jiangsu Research Center for \\ Geotechnical Engineering Technology, Geotechnical Research Institute, Hohai University, Nanjing, China
}

Correspondence should be addressed to Xin Liu; liuxin100@hhu.edu.cn

Received 24 December 2016; Revised 16 February 2017; Accepted 9 March 2017; Published 23 March 2017

Academic Editor: Xiao-Yong Wang

Copyright (C) 2017 Xin Liu et al. This is an open access article distributed under the Creative Commons Attribution License, which permits unrestricted use, distribution, and reproduction in any medium, provided the original work is properly cited.

\begin{abstract}
To promote the utilization of fly-ash, based on the orthogonal experiment method, wet density and unconfined compressive strength of Foamed Mixture Lightweight Soil mixed with fly-ash and quicklime (FMLSF) are studied. It is shown that the wet density and unconfined compressive strength of FMLSF increase with the increase of cement content, while decreasing with the increase of foam content. With the mixing content of fly-ash increase, the wet density and unconfined compressive strength of FMLSF increase firstly and then decrease. Scanning Electron Microscope (SEM) tests show that ball effect or microaggregate effect of fly-ash improves the wet density and unconfined compressive strength of FMLSF. With the mixing content of quicklime increase, the wet density and unconfined compressive strength of FMLSF increase firstly within a narrow range and then decrease. In addition, the primary and secondary influence order on wet density and 28-day compressive strength of FMLSF are obtained, as well as the optimal mixture combination. Finally, based on two abutments in China, behind which they are filled with FMLSF and Foamed Mixture Lightweight Soil (FMLS), the construction techniques and key points of quality control behind abutment are compared and discussed in detail, and the feasibility of utilization fly-ash as FMLSF is verified by the experimental results.
\end{abstract}

\section{Introduction}

Foamed Mixture Lightweight Soil (FMLS) as a new kind of geotechnical material, because of its light weight, independence, self-tightness, regulatory of bulk density and intensity, construction convenience, and thermal insulation properties, and so forth, has been applied successfully in the underground pipeline and cavity filling, heat preservation and heat insulation, and so on, especially in highway embankment filling $[1,2]$. Because of its advantages, FMLS was put forward by Japanese scholars in the early 1980s, and a series of indoor and outdoor experimental research were carried out to show that FMLS is a good material in the field of civil engineering (e.g., [3-6]). Experimental research is mainly focused on compressive strength, stress-strain characteristics, pore structure, fiber improvement, and durability currently [7].
Although a lot of progress has been made, new improved materials for FMLS remain to be studied.

In recent years, fly-ash was gradually used in road engineering, ocean engineering, and other types of engineering. Predecessors (e.g., [8-12]) had done research on the utilization of fly-ash, and some beneficial conclusions were obtained. In general, previous scholars' research showed that fly-ash utilization research usually focuses on using fly-ash as the solely material for embankment filling, while research on the combination of FMLS and fly-ash for embankment filling is less. Using fly-ash as solely material for embankment filling may cause the following problems. Firstly, the dry density of fly-ash after roller compaction is $10.7-11.0 \mathrm{kN} / \mathrm{m}^{3}$, which is a third to fifth lighter than soil, but heavier than widely used FMLS to more than $50 \%$. Therefore, there is a big disadvantage if considering embankment weight. Secondly, fly-ash is 
the powder material in the process of filling, and the compaction effect is not very ideal [13]; especially when its moisture content is higher, the degree of compaction is hard to meet the requirements. In addition, the permeability of flyash is high and easily induces fly-ash being washed by rainwater, so it needs to do package-edge processing with cohesive soil before construction, which will impact the integrity, strength, and stability of embankment [14]. Some scholars (e.g., [15-18]) tried mixing fly-ash with soil or cement, even lightweight aggregate, and proved that it is not only a good way to promote the utilization of fly-ash, but also a good way to solve the above-mentioned problems. Despite recent progress, the research on mixing fly-ash with FMLS is less, so the main point of this work is to explore the best utilization program of fly-ash mixed in FMLS.

The differential settlement between the rigid abutment and the flexible embankment has resulted in huge maintenance costs for the bridge highway, which prompts some experts to find a lightweight and low-cost backfill material for the abutment to effectively solve the problem of strength and deformation. Alizadeh et al. $[19,20]$ used fly-ash to produce a suitable controlled low strength material as a backfill for bridge abutment. The application of argil fly-ash concrete to highway-bridge abutment backfill was introduced by Zhesheng et al. [21] and proved that its soil pressure and settlement are smaller than that of other materials markedly. Li and Zhang [22] and Jamnongpipatkul et al. [23] discussed the actual application state of FMLS in handling of road foundation and showed that FMLS is a lightweight, environmentally friendly embankment backfill material and it can reduce settlement and maintain stability. However, there is little research and application on FMLS mixed with fly-ash and quicklime (FMLSF) as abutment backfill. This paper will study the application of FMLSF in abutment backfill.

This paper starts from the experimental study on wet density and unconfined compressive strength of FMLS mixed with fly-ash and quicklime (FMLSF) based on the orthogonal experiment method $[24,25]$. Then, changing laws of wet density and unconfined compressive strength are revealed, with different content of cement, fly-ash, quicklime, and foam. After that, the microscopic mechanism of fly-ash improvement in FMLSF and primary and secondary influence order of mixing content are obtained later, as well as the optimal mixture combination. Finally, selected sections of abutments of expressway bridge are filled with FMLSF, and the corresponding construction techniques and key points of quality control are discussed.

\section{Mixture Proportion Experiment Program}

2.1. Dosage of Water and Foaming Solution. Define $V_{s}$ as the total volume of slurry composed of cement, fly-ash, quicklime, and water in $1 \mathrm{~m}^{3}$ mixture of FMLSF. It can be showed as follows:

$$
V_{s}=\frac{M_{c}}{\rho_{c}}+\frac{M_{\mathrm{fa}}}{\rho_{\mathrm{fa}}}+\frac{M_{q}}{\rho_{q}}+\frac{M_{w}}{\rho_{w}},
$$

where $M_{c}, M_{\mathrm{fa}}, M_{q}$, and $M_{w}$ are the mass of cement, fly-ash, quicklime, and water, respectively, and $\rho_{c}, \rho_{\mathrm{fa}}, \rho_{q}$, and $\rho_{w}$ are the density of cement, fly-ash, quicklime, and water, respectively, which are $3100 \mathrm{~kg} / \mathrm{m}^{3}, 2600 \mathrm{~kg} / \mathrm{m}^{3}, 1200 \mathrm{~kg} / \mathrm{m}^{3}$, and $1000 \mathrm{~kg} / \mathrm{m}^{3}$, respectively. The dosage of water can be expressed using following equation:

$$
M_{w}=\varphi\left(M_{c}+M_{\mathrm{fa}}+M_{q}\right)
$$

where $\varphi$ is water-binder ratio. The designing density of slurry composed of cement, fly-ash, quicklime, and water is around $1650 \mathrm{~kg} / \mathrm{m}^{3}$, so the water-binder ratio $\varphi$ could be calculated using following equation:

$$
\begin{aligned}
& \rho_{s}=\frac{M_{s}}{V_{s}}=\frac{M_{c}+M_{\mathrm{fa}}+M_{q}+M_{w}}{V_{s}} \\
& =\frac{(1+\varphi)\left(M_{c}+M_{\mathrm{fa}}+M_{q}\right)}{M_{c} / \rho_{c}+M_{\mathrm{fa}} / \rho_{\mathrm{fa}}+M_{q} / \rho_{q}+\varphi\left(M_{c}+M_{\mathrm{fa}}+M_{q}\right) / \rho_{w}},
\end{aligned}
$$

where $\rho_{s}$ is the density of slurry composed of cement, fly-ash, quicklime, and water and $M_{s}$ is the mass of slurry composed of cement, fly-ash, quicklime, and water. The residual volume for $V_{p}$ in $1 \mathrm{~m}^{3}$ mixture of FMLSF would be filled by foam, so the dosage of foaming solution $V_{p}$ would be calculated using the following equation:

$$
V_{p}=K\left(1-V_{s}\right) \text {, }
$$

where $K$ is extracoefficient, usually taking 1.1 1.3. $K=1.1$ in this experiment. We firstly did some preexperiments to decide the suitable dosage of foaming solution based on above calculation. Because of lots of losses of foam when added to the mixture of FMLSF, we should add 2 3 times the amount of theoretical foam to get the ideal porosity content or specific density.

2.2. Orthogonal Experiment Method. The composition of FMLSF can be divided into two classes: one is the main components as cement, water, and foam, and the other is auxiliary components as fly-ash, quicklime, and others. For the wet density and unconfined compressive strength of FMLSF, the main affecting factors are cement, fly-ash, quicklime, and foam. Each affecting factor is set four levels further in Table 1, using $L_{16}\left(4^{4}\right)$ orthogonal table to arrange four factors and four levels of tests in Table 2.

\subsection{Experimental Materials and Instruments. A Composite} Polymer Foaming Agent (CPFA) is used to produce FMLSF in this research, which is a colorless liquid, and $\mathrm{PH}$ value is 7.5-9.0. It has many advantages, such as high foaming rate, low absorption rate, high strength, and persistence. In addition, CPFA is pollution-free and green environmental. There are two methods to form air bubbles: mechanical mixing method and prefoaming method. To control the amount and stability of air bubbles, the prefoaming method is selected. With the prefoaming method, the air bubbles were first foamed via a foaming machine and then mixed with cement 
TABLE 1: Four levels of each affecting factor.

\begin{tabular}{lcccc}
\hline Level & Cement $\left(\mathrm{kg} / \mathrm{m}^{3}\right)$ & Fly-ash $\left(\mathrm{kg} / \mathrm{m}^{3}\right)$ & Quicklime $\left(\mathrm{kg} / \mathrm{m}^{3}\right)$ & Foam $(\mathrm{L})$ \\
\hline 1 & 250 & 50 & 10 & 850 \\
2 & 400 & 100 & 20 & 750 \\
3 & 550 & 150 & 30 & 650 \\
4 & 700 & 200 & 40 & 550 \\
\hline
\end{tabular}

TABLE 2: $L_{16}\left(4^{4}\right)$ orthogonal table.

\begin{tabular}{lcccccc}
\hline \multirow{2}{*}{ Test number } & \multicolumn{2}{c}{ Affecting factor } & & & \multicolumn{2}{c}{ Test results } \\
Unconfined compressive strength $(\mathrm{MPa})$
\end{tabular}

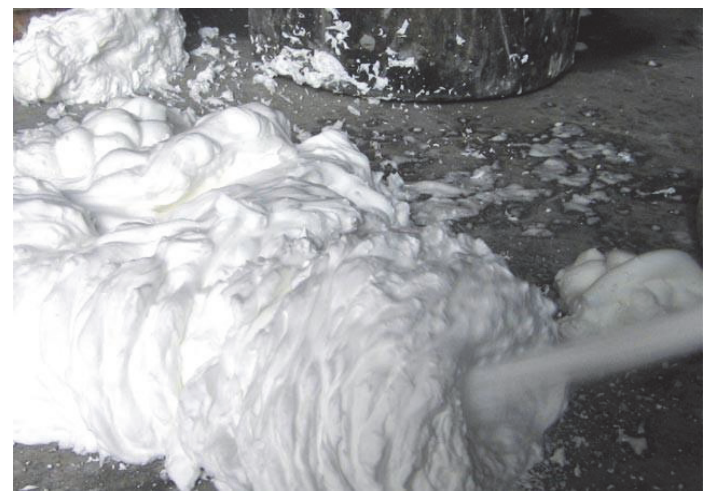

Figure 1: Generated bubbles.

slurry. CPFA is mixed with water according to the scale of 1:40. Generated bubbles are shown in Figure 1. The fly-ash used in this work is collected from Yulian thermal power plant in Henan, China. According to the test result, the $45 \mu \mathrm{m}$ sieve residues of fly-ash are $12 \%$, which meet the fineness requirement of ASTM C618 [26]. The hardening agent is ordinary Portland cement whose grade is 42.5 . Table 3 shows the chemical and mineralogical compositions of cement and fly-ash used in this investigation, and Table 4 shows the physical properties of cement which meet the requirements of ASTM C311 [27].
TABLE 3: Chemical compositions of cement and fly-ash.

\begin{tabular}{lcc}
\hline Chemical constituents & Cement (\%) & Fly-ash (\%) \\
\hline Silicon dioxide/silica $\left(\mathrm{SiO}_{2}\right)$ & 20.32 & 57.2 \\
Aluminium oxide/alumina $\left(\mathrm{Al}_{2} \mathrm{O}_{3}\right)$ & 4.86 & 29.1 \\
Ferric oxide $\left(\mathrm{Fe}_{2} \mathrm{O}_{3}\right)$ & 4.99 & 4.3 \\
Calcium oxide $(\mathrm{CaO})$ & 65.45 & 1.5 \\
Magnesium oxide $(\mathrm{MgO})$ & 1.25 & 2.8 \\
Sodium oxide $\left(\mathrm{Na}_{2} \mathrm{O}\right)$ & 0.15 & 3.2 \\
Potassium oxide $\left(\mathrm{K}_{2} \mathrm{O}\right)$ & 0.40 & 1.2 \\
Sulphur oxide $\left(\mathrm{SO}_{3}\right)$ & 2.10 & 0.7 \\
\hline
\end{tabular}

TABle 4: Physical properties of cement.

\begin{tabular}{lc}
\hline Physical properties & Test results \\
\hline Specific surface, $\mathrm{m}^{2} / \mathrm{kg}$ & 256 \\
Compressive strength, $\mathrm{MPa}$ & 28.8 (3 days) $/ 45.3$ (28 days) \\
Initial set, minutes & 165 \\
Final set, minutes & 232 \\
Water consumption of normal & 25.6 \\
consistency $(\%)$ & 1.2 \\
Fineness $(80 \mu \mathrm{m}, \%)$ & \\
\hline
\end{tabular}

Materials and samples preparation, as well as measurement of wet density and unconfined compressive strength, are 


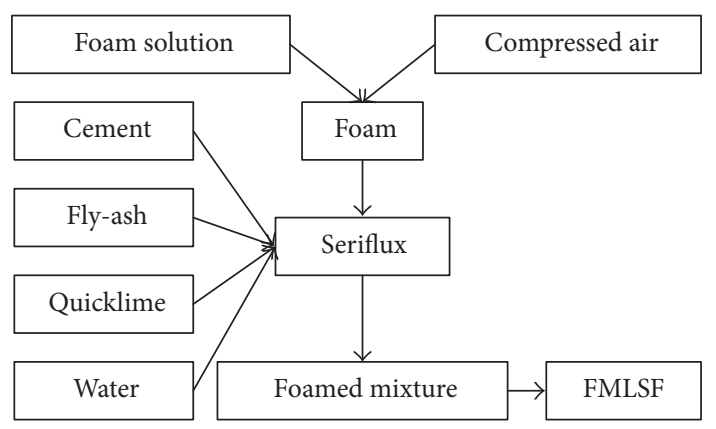

FIGURE 2: The specimen preparation process.

conducted according to the Chinese Standard of Technical Specification for Foamed Mixture Lightweight Soil Filling Engineering [28]. Firstly, the cement content, quicklime content, and fly-ash content are mixed according to the orthogonal experimental design of 16 different mix proportion groups. Stirring time lasts approximately $5 \mathrm{~min}$ and then stirring with water, until seriflux's wet density is around $1650 \mathrm{~kg} / \mathrm{m}^{3}$. This process is very important, because cement and fly-ash must be fully mixed into slurry state until the seriflux no longer contains larger particles. Secondly, the foaming agent is diluted with water in a ratio of $1: 40$, and then frothing through foaming machine. Thirdly, the generated bubbles are added to fully stirred seriflux, then loading the foamed mixture into cube mould whose size is $10 \mathrm{~cm} \times 10 \mathrm{~cm} \times 10 \mathrm{~cm}$ after mixing for 5 minutes. Because foamed mixture has high liquidity, it can fully dense as long as mould vibration gently. Finally, put samples covered with plastic film in an incubator chamber at $20^{\circ} \mathrm{C}$, demould after conserving 24 hours, then number them, and conserve to designing age. Before the foamed mixture loaded into cube mould, it was measured to obtain its wet density. Three specimens were tested and the average wet density was computed. The wet density is measured by a container and an electronic weigher; the range of them, respectively, is $600 \mathrm{~mL}$ and $2000 \mathrm{~g}$. Three specimens were tested at the age of $28 \mathrm{~d}$ to determine their unconfined compressive strength and the average strength was computed. The unconfined compressive strength is measured by electronic universal testing machine which is made in Changchun Machinery Factory (CSS-44050) and the loading rate is $2 \mathrm{kN} / \mathrm{s}$.

The specimen preparation process is shown in Figure 2. Samples before demoulding are shown in Figure 3. Different mixture proportions of FMLSF which have been numbered are shown in Figure 4.

\section{Analysis of Test Results}

Unconfined compressive strength test results of FMLSF are shown in Table 2. To compare the effect of various factors on the strength and wet density, we calculated the mean value of strength and wet density at different levels of each affecting factor; the results are shown in Figures 5-9. To investigate the microscopic mechanism of fly-ash improvement, the microstructure of FMLSF at different cement content was

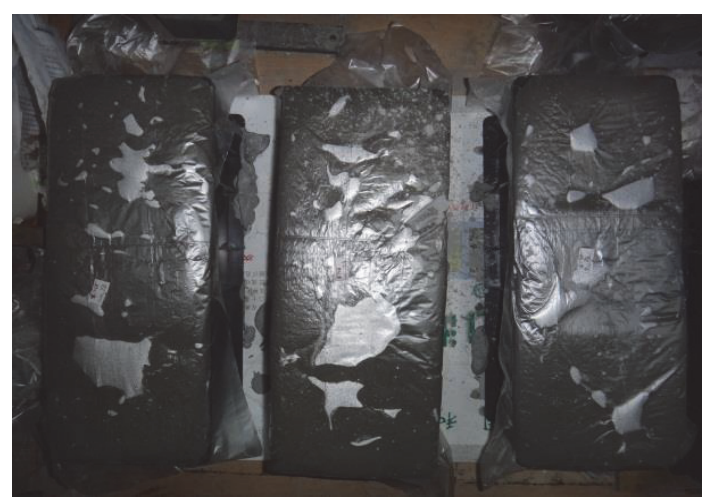

FIGURE 3: Samples before demoulding.

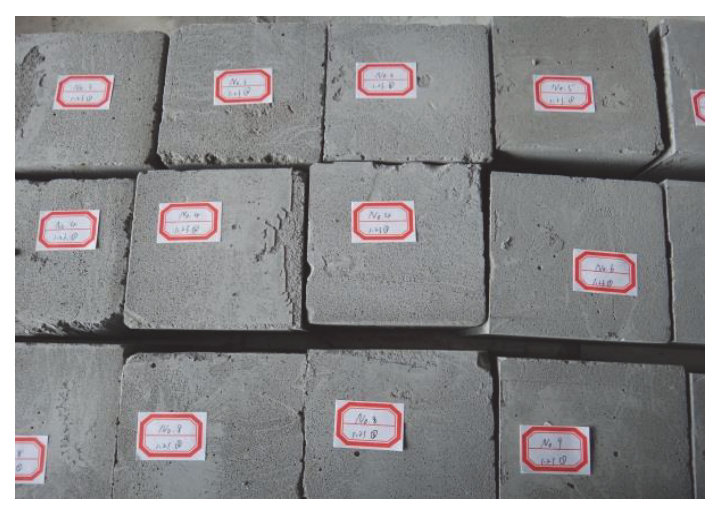

FIGURE 4: Different mixture proportion of FMLSF which have been numbered.

observed by Scanning Electron Microscope (SEM), and the representative images are shown in Figure 6.

As can be seen from the Figure 5, the wet density and unconfined compressive strength of FMLSF increase with the increase of cement content. It is well known that cement is a cementitious material. For FMLSF, cement is the primary cementitious material and the primary source of strength. We all know that hydration occurs when cement encounters water. Hydration is the precondition of cement hardening and hardening is the reason for the structural strength. The hydration products of cement are mainly amorphous calcium silicate hydrates (C-S-H), cubic plate of calcium hydroxide crystals, and needle-like ettringite (see Figure 6(b)). These hydrated products grow interchangeably, making the structure become compacted and dense.

As can be seen from the Figure 7, the addition of fly-ash makes the wet density and unconfined compressive strength of FMLSF increase firstly and then decrease. Fly-ash particles are smooth spherical beads, which are similar to the lubrication effect of ball bearing that can reduce the friction between particles. It is well known that the flowability of spherical particles in the slurry is much greater than that of any other shaped particles under the identical conditions. Furthermore, the $45 \mu \mathrm{m}$ sieve residues are used as fly-ash fineness requirements according to the ASTM C 618. That is to say, most of the particle size of fly-ash is less than $45 \mu \mathrm{m}$. 


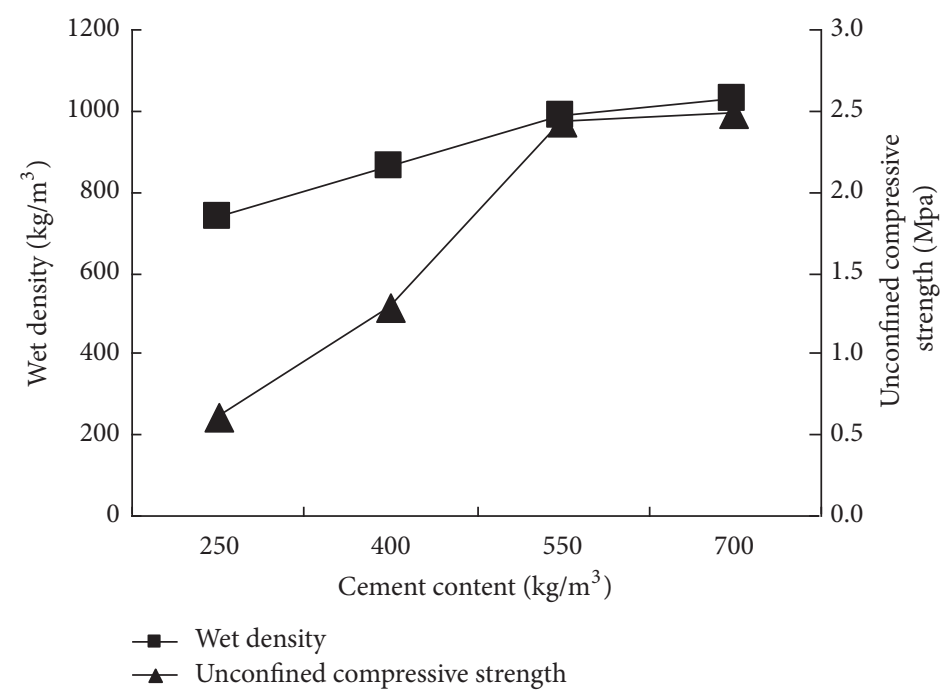

FIGURE 5: Cement content's influence on wet density and strength of FMLSF.

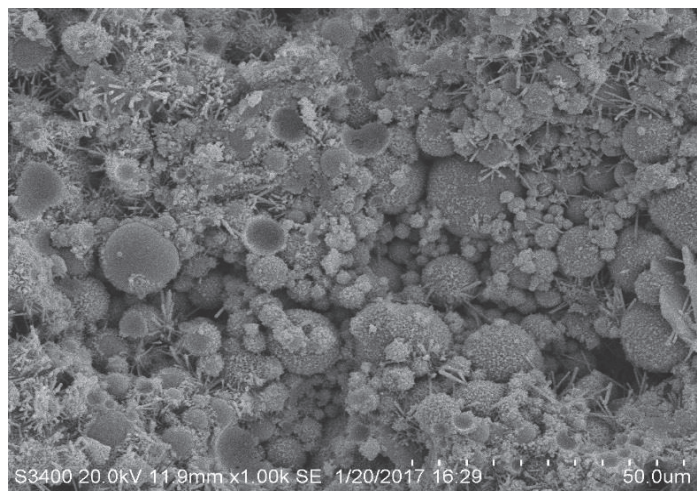

(a) Cement content is $55 \%$ (fly-ash $45 \%$ )

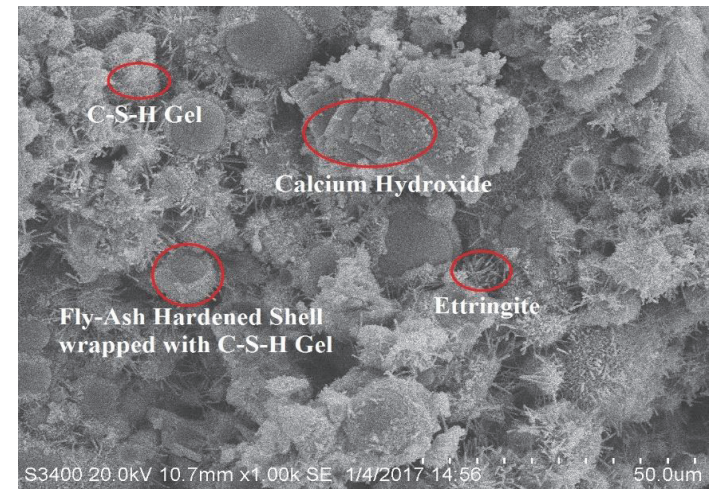

(b) Cement content is $75 \%$ (fly-ash $25 \%$ )

FIGURE 6: The SEM images of FMLSF: 1000x.

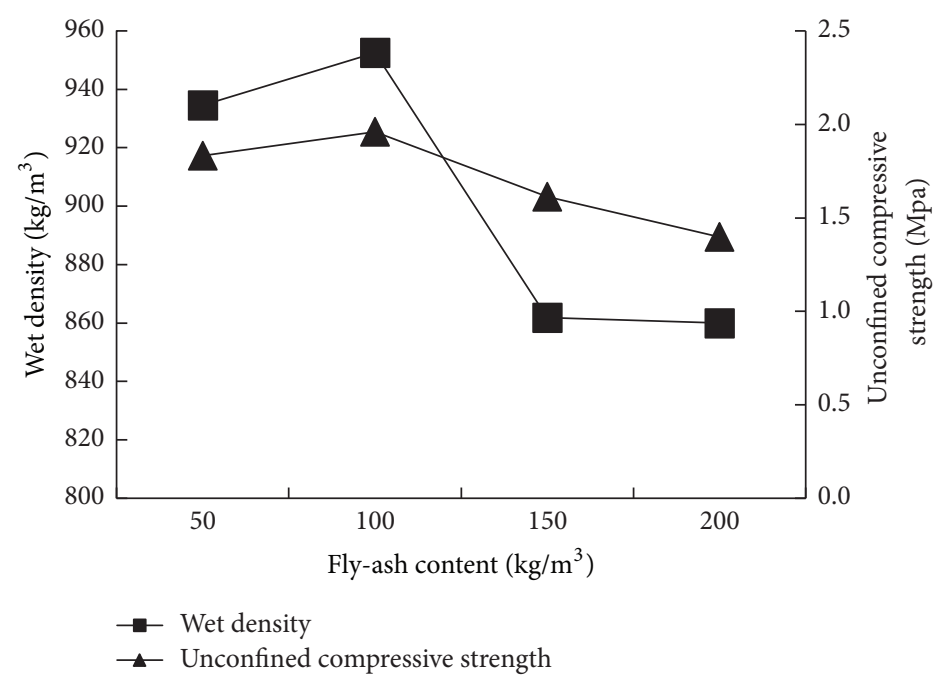

FIGURE 7: Fly-ash content's influence on wet density and strength of FMLSF. 


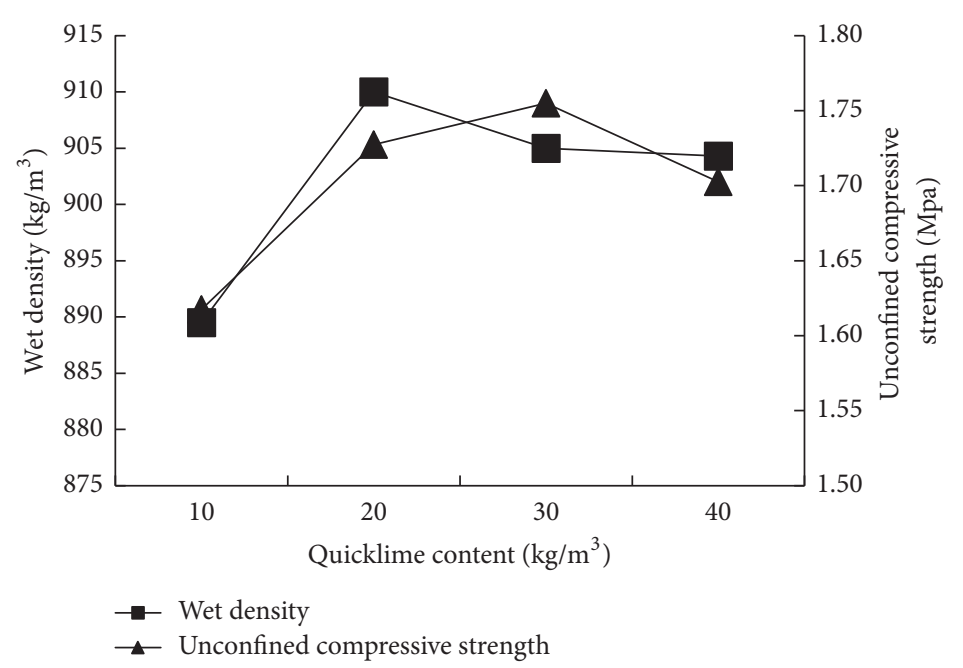

FIGURE 8: Quicklime content's influence on wet density and strength of FMLSF.

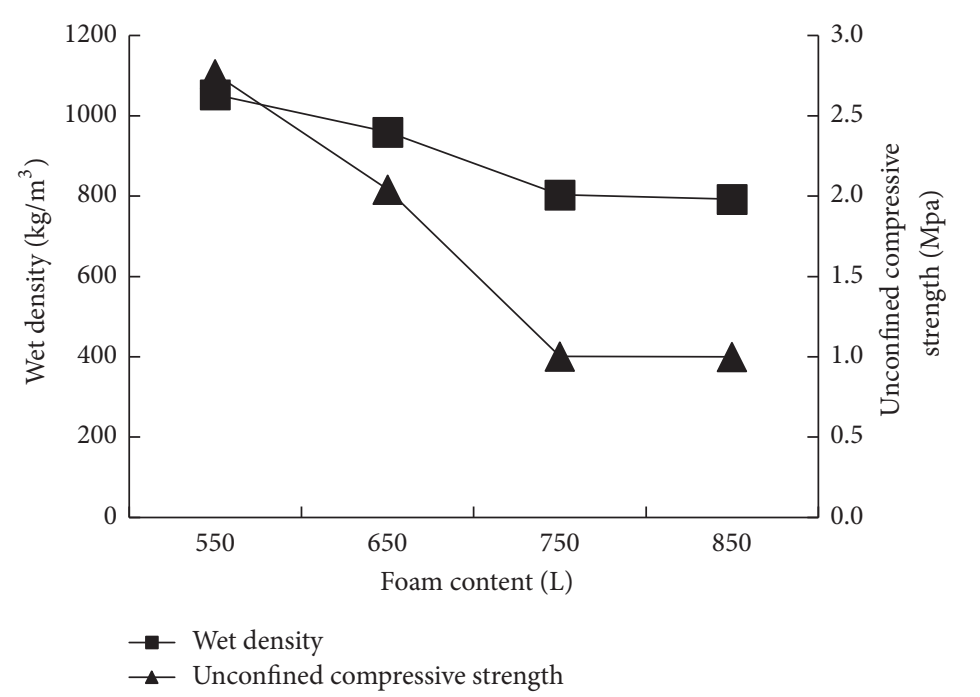

FIGURE 9: Foam content's influence on wet density and strength of FMLSF.

Because of the small size of fly-ash particles and the shape of smooth spherical beads, as is shown in Figure 6(a), the fly-ash particles can be evenly distributed in the cement slurry, which makes the cement particles evenly disperse to reduce the accumulation of cement. As a result, space of hydration and generated hydration products is expanded and the porosity after hardening is reduced. The description of the preceding paragraph is called ball effect or microaggregate effect of fly-ash. With the ball effect (e.g., [29-33]), the structure between spherical particles of fly-ash and cement particles can be closer, thus improving the wet density and unconfined compressive strength of FMLSF to a certain extent. However, when the fly-ash content is small, the ball effect is not obvious. Meanwhile, excessive fly-ash content will lead to less hydration products and as a result reduce wet density and strength. So too much fly-ash has little good effect on wet density or strength; there is an optimal value.
As can be seen from the Figure 8, with the mixing content of quicklime increase, the wet density and unconfined compressive strength of FMLSF increase firstly within a narrow range and then decrease. It follows that quicklime has little effect on wet density and strength, so it should not be used as the additive agent for FMLSF. As is reported by Cong and Bing [34], the water existing in the surface of the foam can be assimilated by quicklime, which results in the breaking of foam. The great instability in foam is also the reason that quicklime cannot be applied in the FMLSF.

As can be seen from the Figure 9, the increase of foam content makes the wet density and unconfined compressive strength of FMLSF decrease. It is because with the increase of foam content, the amount of fine closed foams in the slurry increases. Thus, the slurry volume will increase, which leads to decreasing of wet density and strength. Based on Kikuchi' microscopic observation [35], the air voids in the FMLS will 
TABLE 5: The range analysis results.

\begin{tabular}{|c|c|c|c|c|}
\hline \multirow{2}{*}{ Level parameters } & \multicolumn{4}{|c|}{ Affecting factor } \\
\hline & Cement & Fly-ash & Quicklime & Foam \\
\hline \multicolumn{5}{|l|}{ Wet density } \\
\hline$k_{j 1}$ & 734.5 & 934.5 & 889.5 & 792.5 \\
\hline$k_{j 2}$ & 856.8 & 952.5 & 910.0 & 803.8 \\
\hline$k_{j 3}$ & 987.5 & 861.8 & 905.0 & 960.0 \\
\hline$k_{j 4}$ & 1030.0 & 860.0 & 904.3 & 1052.5 \\
\hline$R_{j}$ & 295.5 & 92.5 & 20.5 & 260.0 \\
\hline Sensitivity sequence & \multicolumn{4}{|c|}{ Cement $>$ foam $>$ fly-ash $>$ quicklime } \\
\hline \multicolumn{5}{|l|}{ Compressive strength } \\
\hline$k_{j 1}$ & 0.605 & 1.833 & 1.618 & 1.000 \\
\hline$k_{j 2}$ & 1.285 & 1.960 & 1.728 & 1.003 \\
\hline$k_{j 3}$ & 2.425 & 1.613 & 1.755 & 2.040 \\
\hline$k_{j 4}$ & 2.488 & 1.398 & 1.703 & 2.760 \\
\hline$R_{j}$ & 1.883 & 0.563 & 0.138 & 1.760 \\
\hline Sensitivity sequence & \multicolumn{4}{|c|}{ Cement $>$ foam $>$ fly-ash $>$ quicklime } \\
\hline
\end{tabular}

be connected when the air fraction is more than $30 \%$ by volume; it is disadvantageous for the strength of FMLS. Foam reduces the wet density but also reduces the strength, so the foam content should not be too high.

\section{Range Analyses}

The factors which influence wet density and strength of FMLSF include cement content, fly-ash content, quicklime content, and foam content. It can found through experiments that four factors have different level of effects on wet density and strength. In order to analyze magnitude of the effect, the range analysis method is selected, and the results are shown in Table 5 . It can be seen from it that the main factor which influences wet density and compressive strength is the cement content, which follows the foam content. Therefore, the cement content and foam content should be strictly controlled to achieve the purpose of controlling construction quality. The calculation steps of range analysis are as follows:

(1) Calculate $K_{j m}$ value, where $K_{j m}$ is the sum of corresponding test results for affecting factor in different level; $m$ is serial number of levels of affecting factor, as $1,2,3$, and $4 ; j$ is serial number of affecting factors, as $1,2,3$, and 4 .

(2) Calculate $k_{j m}$ value, where $k_{j m}=K_{j m} / 4, m=1,2,3,4$.

(3) Calculate the range value $R_{j}$ of $k_{j m}$, where $R_{j}=$ $\max \left(k_{j m}\right)-\min \left(k_{j m}\right)$.

(4) According the value of $R_{j}$, judge the influence order of affecting factors.

The greater the value, the larger the influence on test results and the more important the affecting factor.

\section{The Optimum Mixture Proportion}

From the view of engineering application, in general, the mixture proportion of FMLSF when wet density is low $\left(<1000 \mathrm{~kg} / \mathrm{m}^{3}\right)$ and strength is high $(>1 \mathrm{MPa})$ is the optimum mix proportion, therefore taking the data of Table 3 for further analysis.

(1) Cement. The corresponding compressive strengths of $400 \mathrm{~kg} / \mathrm{m}^{3}, 550 \mathrm{~kg} / \mathrm{m}^{3}$, and $700 \mathrm{~kg} / \mathrm{m}^{3}$ are all greater than $1 \mathrm{MPa}$. However, with the increase of mixing amount, the corresponding cost increases also. As a result, the recommended optimal mixing proportion of cement is $400 \mathrm{~kg} / \mathrm{m}^{3}$, and the corresponding wet density also meets the requirement.

(2) Foam. $650 \mathrm{~L} / \mathrm{m}^{3}$ and $750 \mathrm{~L} / \mathrm{m}^{3}$ can meet the requirements. From the point of improving the lightweight, $750 \mathrm{~L} / \mathrm{m}^{3}$ is a better choice.

(3) Fly-Ash. Because all the compressive strength of different addition amounts can meet the requirements, it is suitable for analysis through wet density. It is not difficult to find that $150 \mathrm{~kg} / \mathrm{m}^{3}$ and $200 \mathrm{~kg} / \mathrm{m}^{3}$ are more reasonable. From the view of promoting the use of fly-ash, $200 \mathrm{~kg} / \mathrm{m}^{3}$ is a better choice.

(4) Quicklime. Both the wet density and compressive strength changed very little, so it is better not to mix quicklime.

\section{As Backfill Material behind Abutments of Expressway Bridge}

6.1. General Situation of the Engineering. The experimental engineering named Guang-Fo-Zhao Expressway Lianjing Bridge is located in Zhaoqing City, Guangdong Province, China. The roadway station is $\mathrm{K} 80+679.679-\mathrm{K} 80+760.116$, 
TABLE 6: Mixture proportion in the practical engineering of FMLS.

\begin{tabular}{lccccc}
\hline Number & $\begin{array}{c}\text { Cement } \\
\left(\mathrm{kg} / \mathrm{m}^{3}\right)\end{array}$ & $\begin{array}{c}\text { Water } \\
\left(\mathrm{kg} / \mathrm{m}^{3}\right)\end{array}$ & $\begin{array}{c}\text { Foam } \\
(\mathrm{L})\end{array}$ & $\begin{array}{c}\text { Wet density of FMLS } \\
\left(\mathrm{kg} / \mathrm{m}^{3}\right)\end{array}$ & $\begin{array}{c}\text { Foam ratio } \\
(\%)\end{array}$ \\
\hline 1 & 600 & 352.1 & 500 & 970 & $44.89 \%$ \\
2 & 500 & 293.4 & 600 & 800 & $54.55 \%$ \\
3 & 400 & 234.7 & 700 & 720 & $59.09 \%$ \\
4 & 350 & 205.4 & 750 & 620 & $64.77 \%$ \\
\hline
\end{tabular}

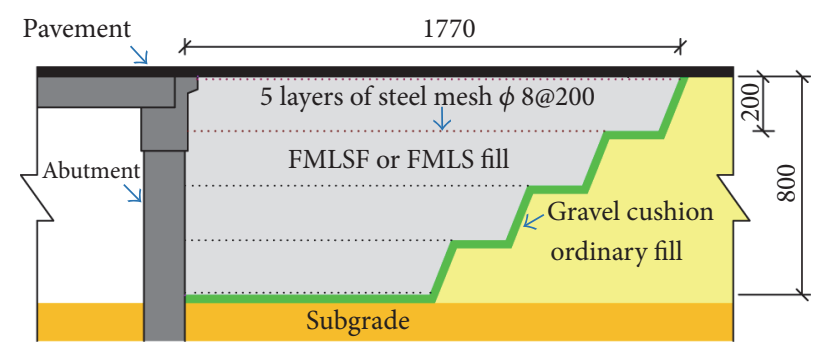

FIGURE 10: Filling diagram of FMLSF or FMLS as backfill material behind abutments.

and it is a separate abutment. Behind the abutments of Lianjing Bridge, FMLSF or FMLS are filled as backfill material, so as to reduce the load and basic stress, reduce settlement, and increase the dense of fillings $[36,37]$. In order to verify the optimum mixture proportion of FMLSF based on laboratory experimental data in this article, two abutments are selected to fill with FMLSF and FMLS, respectively. The height behind the abutment is $8 \mathrm{~m}$, width is $12 \mathrm{~m}$, and length is $17.7 \mathrm{~m}$. Along the longitudinal of the road, four steps with spacing $2 \mathrm{~m}$ are set at the joint of the FMLSF and subgrade. Each step laid steel mesh as $\phi 8 @ 200$ to reinforce the integrity and stability of FMLSF and subgrade. Filling diagram of FMLSF or FMLS as backfill material behind abutments is shown in Figure 10.

6.2. Construction Technology. The construction technology of FMLSF and FMLS is almost the same, and the key points of quality control are briefly analyzed as follows. According to the previous studies on FMLS, because its fluidity is high, the pouring method can be selected, and there is a wealth of construction data of FMLS [38]. Single layer thickness of the pouring for FMLSF is $0.6 \mathrm{~m}$ and FMLS is $0.8 \mathrm{~m}$. Single layer time of the pouring should be controlled in the concrete initial setting time. A layer of pouring should be after the final set of the under layer, so the time interval is at least 7 hours. Avoid the rain, in the process of construction, and curing at moisture-retention with plastic film or nonwoven fabric.

Before filling construction, testing preparation of four practical engineering mixture proportions of FMLS is conducted, and the results are shown in Table 6. Testing preparation of mixture proportion of FMLSF is the same as laboratory experiments. Because foam density is far less than the cement density, this paper uses the same wet density cement slurry by adding different amount of foam content to pouring specimens. Material composition of cement slurry is as follows: cement $1109.2 \mathrm{~kg} / \mathrm{m}^{3}$, water $650.9 \mathrm{~kg} / \mathrm{m}^{3}$, and wet density $1760.1 \mathrm{~kg} / \mathrm{m}^{3}$.
6.3. Fieldwork Experiment Results. See Figure 11 for the results of unconfined compressive strength test of FMLS. Through the stress-strain curves with different rate of foam, it can be seen that the unconfined compressive strength of FMLS decreases with the rate of foam increase. In addition, main failure pattern which is brittle failure is gradually transformed into ductile failure. When compressive strength meets the design requirements, wet density of FMLS should be as small as possible, so the first (wet density $970 \mathrm{~kg} / \mathrm{m}^{3}$; unconfined compressive strength $1.4 \mathrm{MPa}$ ) or second (wet density $800 \mathrm{~kg} / \mathrm{m}^{3}$; unconfined compressive strength $1.2 \mathrm{MPa}$ ) group is more appropriate. Furthermore, according to the optimum mixture proportion of FMLSF (cement $400 \mathrm{~kg} / \mathrm{m}^{3}$, fly-ash $200 \mathrm{~kg} / \mathrm{m}^{3}$, and foam $750 \mathrm{~L} / \mathrm{m}^{3}$ ) to prepare sample and do unconfined compressive strength test, experimental results show that wet density of FMLSF is $720 \mathrm{~kg} / \mathrm{m}^{3}$, and compressive strength is $1.4 \mathrm{MPa}$.

Based on the above test results, two mixture proportions are used to manufacture FMLS and FMLSF as backfill material, respectively. The recent monitor report shows that the settlement and stability of the two abutments all meet the requirements. Because of the low price of fly-ash and because utilization of it can reduce the pollution of environment, from this point of view, FMLSF is better than FMLS.

\section{Conclusions}

Foamed Mixture Lightweight Soil mixed with fly-ash and quicklime as backfill material behind abutments of expressway bridge is studied in this paper. Based on two abutments of Guang-Fo-Zhao Expressway Bridge in China, the construction techniques and key points of quality control filled with FMLSF behind abutment are proposed as follows:

(1) The wet density and unconfined compressive strength of FMLSF increase with the increase of cement content, while decreasing with the increase of foam 


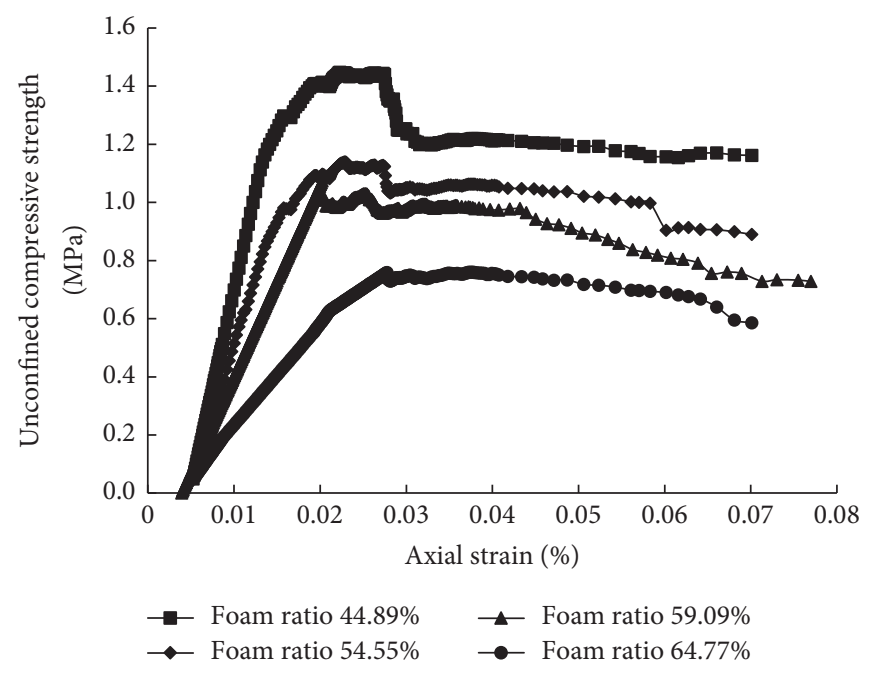

FIGURE 11: The stress-strain curves of FMLS with different rate of foam.

content. With the mixing content of fly-ash increase, the wet density and unconfined compressive strength of FMLSF increase firstly and then decrease. With the mixing content of quicklime increase, the wet density and unconfined compressive strength of FMLSF increase firstly within a narrow range and then decrease.

(2) The microscopic mechanism of fly-ash improvement in FMLSF is investigated through images observed by Scanning Electron Microscope (SEM). Ball effect or microaggregate effect of fly-ash improves the wet density and unconfined compressive strength of FMLSF.

(3) The range analysis shows that the content of cement has a significant effect on the wet density and unconfined compressive strength and then in turn air content, fly-ash content, and quicklime content. The optimum mixture proportion is cement $400 \mathrm{~kg} / \mathrm{m}^{3}$, fly-ash $200 \mathrm{~kg} / \mathrm{m}^{3}$, and foam $750 \mathrm{~L} / \mathrm{m}^{3}$.

(4) The settlement and stability of the two abutments filled with FMLSF and FMLS all meet the requirements. Because of the low price of fly-ash and because utilization of it can reduce the pollution of environment, from this point of view, FMLSF is better than FMLS.

\section{Nomenclature}

$\begin{array}{ll}V_{s}: & \begin{array}{l}\text { Volume of slurry without bubbles (see } \\ (1))\end{array} \\ V_{p}: & \text { Dosage of foaming solution (see (4)) } \\ M_{c}, M_{\mathrm{fa}}, M_{q}, M_{w}: & \begin{array}{l}\text { Mass of cement, fly-ash, quicklime, and } \\ \text { water, respectively }\end{array} \\ M_{s}: & \begin{array}{l}\text { Mass of slurry composed of cement, } \\ \text { fly-ash, quicklime, and water }(\mathrm{see}(3))\end{array} \\ \rho_{c}: & \text { Density of cement }\left(=3100 \mathrm{~kg} / \mathrm{m}^{3}\right) \\ \rho_{\mathrm{fa}}: & \text { Density of fly-ash }\left(=2600 \mathrm{~kg} / \mathrm{m}^{3}\right) \\ \rho_{q}: & \text { Density of quicklime }\left(=1200 \mathrm{~kg} / \mathrm{m}^{3}\right)\end{array}$

$\rho_{w}: \quad$ Density of water $\left(=1000 \mathrm{~kg} / \mathrm{m}^{3}\right)$

$\rho_{s}$ : Density of slurry without bubbles $\left(=1650 \mathrm{~kg} / \mathrm{m}^{3}\right)$

$\varphi$ : Water-binder ratio (see (2))

$K: \quad$ Extracoefficient $(=1.1)$

$j$ : $\quad$ Serial number of affecting factors

$m$ : Serial number of levels of affecting factor

$K_{j m}$ : The sum of affecting factor in different level

$k_{j m}$ : Average value $\left(=K_{j m} / 4\right)$ (see Table 3$)$

$R_{j}$ : Range value $\left(=\max \left(k_{j m}\right)-\min \left(k_{j m}\right)\right)$ (see Table 3$)$.

\section{Additional Points}

Research Highlights. (i) Promote the utilization of fly-ash mixed in Foamed Mixture Lightweight Soil (FMLS), as backfill material behind abutments of expressway bridge. (ii) The influence laws of cement content, air content, fly-ash content, and quicklime content on the wet density and $28 \mathrm{~d}$ unconfined compressive strength of Foamed Mixture Lightweight Soil mixed with fly-ash and quicklime (FMLSF) are revealed. (iii) The microscopic mechanism of fly-ash improvement in FMLSF is investigated. (iv) The primary and secondary influence order on wet density and $28 \mathrm{~d}$ compressive strength of FMLSF are obtained, as well as the optimal mixture combination. (v) The construction technology of FMLSF and FMLS as backfill material behind abutments of expressway bridge is studied.

\section{Conflicts of Interest}

The authors declare that they have no conflicts of interest.

\section{Acknowledgments}

This study was sponsored by the National Natural Science Foundation of China (no. 51609071), the Natural Science Foundation of Jiangsu Province China for Youth (Grant no. BK20140848), the Fundamental Research Funds for the 
Central Universities (no. 2015B06014), and Science and Technology Project of Guangdong Provincial Communications Department of China (2015-02-013).

\section{References}

[1] S.-C. Ng, K.-S. Low, and N.-H. Tioh, "Potential use of clayey soil in aerated lightweight concrete," KSCE Journal of Civil Engineering, vol. 16, no. 5, pp. 809-815, 2012.

[2] G. Wang, L. Sha, and F. Jin, "Study on the strength properties and failure mode of recycled sludge lightweight soil," Applied Mechanics and Materials, vol. 275-277, pp. 1281-1284, 2013.

[3] A. Sedláková and M. A. Ali, "Composite materials based on lightweight concrete," Chemicke Listy, vol. 105, no. 16, pp. s445s447, 2011.

[4] Y. Watabe, T. Noguchi, and Y. Mitarai, "Use of cement-treated lightweight soils made from dredged clay," Journal of ASTM International, vol. 9, no. 4, pp. 15-31, 2012.

[5] W. J. Yang and Q. S. Li, "Application and research on new technology of foam lightweight soil in treatment of soft soil foundation of railway engineering," Applied Mechanics and Materials, vol. 204-208, pp. 1622-1625, 2012.

[6] Y. T. Kim, J. Ahn, W. J. Han, and M. A. Gabr, "Experimental evaluation of strength characteristics of stabilized dredged soil," Journal of Materials in Civil Engineering, vol. 22, no. 5, pp. 539$544,2010$.

[7] C. Zhou, "Mechanical properties the cast in situ foamed lightweight soil," Key Engineering Materials, vol. 703, pp. 411$415,2016$.

[8] S. Horiuchi, M. Kawaguchi, and K. Yasuhara, "Effective use of fly ash slurry as fill material," Journal of Hazardous Materials, vol. 76, no. 2-3, pp. 301-337, 2000.

[9] Muhardi, "The performance of fly ash as fill material for embankment model on soft soil," Electronic Journal of Geotechnical Engineering, vol. 20, no. 7, pp. 1699-1710, 2015.

[10] M. Ahmaruzzaman, "A review on the utilization of fly ash," Progress in Energy and Combustion Science, vol. 36, no. 3, pp. 327-363, 2010.

[11] B. González-Corrochano, J. Alonso-Azcárate, and M. Rodas, "Effect of thermal treatment on the retention of chemical elements in the structure of lightweight aggregates manufactured from contaminated mine soil and fly ash," Construction and Building Materials, vol. 35, pp. 497-507, 2012.

[12] Z. T. Yao, X. S. Ji, P. K. Sarker et al., "A comprehensive review on the applications of coal fly ash," Earth-Science Reviews, vol. 141, pp. 105-121, 2015.

[13] K. Zabielska-Adamska, "Laboratory compaction of fly ash and fly ash with cement additions," Journal of Hazardous Materials, vol. 151, no. 2-3, pp. 481-489, 2008.

[14] X. Liu, K. Sheng, J. H. Hua, B. N. Hong, and J. J. Zhu, "Utilization of high liquid limit soil as subgrade materials with packandcover method in road embankment construction," International Journal of Civil Engineering, vol. 13, no. 3-4, pp. 167-174, 2015.

[15] F. Santos, L. Li, Y. Li, and F. Amini, "Geotechnical properties of fly-ash and soil mixtures for use in highway embankments," in Proceedings of the World of Coal Ash (WOCA) Conference, pp. 1-11, Denver, Colo, USA, May 2011.

[16] N. M. Ibrahim, R. C. Amat, S. Salehuddin, N. L. Rahim, A. R. A. Razak, and W. H. Ooi, "Properties of lightweight concrete composites with mixture of fly ash and concrete sludge aggregate," Key Engineering Materials, vol. 594-595, pp. 482-486, 2014.
[17] N. M. Ibrahim, K. N. Ismail, A. R. Abdul Razak et al., "Utilisation of recycled concrete sludge aggregate and fly-ash in the production of lightweight foamed concrete for environmental sustainability," International Proceedings of Chemical Biological \& Environmental, vol. 68, pp. 29-33, 2014.

[18] Y. S. Luo, J. Li, and A. Chan, "Study on the engineering property of mixed-soil fly ash," in Advances in Environmental Geotechnics, pp. 721-727, Springer, Berlin, Germany, 2010.

[19] V. Alizadeh, "The sustainable application of fly ash in bridge abutments," in Geo-Chicago 2016: Sustainable Materials and Resource Conservation, pp. 159-166, Geotechnical Special Publication, 2016.

[20] V. Alizadeh, S. Helwany, A. Ghorbanpoor, and M. Oliva, "Rapidconstruction technique for bridge abutments using controlled low-strength materials," Journal of Performance of Constructed Facilities, vol. 28, no. 1, pp. 149-156, 2014.

[21] G. E. Zhe-sheng, X. M. Huang, X. L. Zhang et al., "Study on application of argil fly-ash concrete to highway-bridge abutment-backfill," Rock \& Soil Mechanics, vol. 27, no. 11, pp. 20762065, 2006.

[22] Z. Li and K. Zhang, "Application and research on new technology of foam lightweight soil in treatment of soft soil foundation of railway engineering," Applied Mechanics and Materials, vol. 204-208, pp. 1622-1625, 2012.

[23] P. Jamnongpipatkul, M. Dechasakulsom, and J. Sukolrat, "Application of air foam stabilized soil for bridge-embankment transition zone in Thailand," in Proceedings of the GeoHunan International Conference: Challenges and Recent Advances in Pavement Technologies and Transportation Geotechnics, pp. 181-193, August 2009.

[24] X. J. Liu and Y. M. Wang, "Study on the workability of selfcompacting lightweight aggregate concrete with orthogonal experiment method," Advanced Materials Research, vol. 415-417, pp. 1503-1507, 2014.

[25] S. Xia, R. Lin, X. Cui, and J. Shan, "The application of orthogonal test method in the parameters optimization of PEMFC under steady working condition," International Journal of Hydrogen Energy, vol. 41, no. 26, pp. 11380-11390, 2016.

[26] ASTM International Standard, ASTM C 618-05, Standard Specification for Coal Fly Ash and Raw or Calcined Natural Pozzolan for Use in concrete.

[27] ASTM International Standard, "Standard test methods for sampling and testing fly ash or natural pozzolans for use in portland-cement concrete," ASTM C 311-05, 2016.

[28] GuangDong GuanSheng Civil Engineering Technology Co. LTD, "Technical specification for foamed mixture lightweight soil filling engineering," Tech. Rep. CJJ/T 177-2012, China Architecture \& Building Press, Beijing, China, 2012.

[29] H. Li, D. Xu, S. Feng, and B. Shang, "Microstructure and performance of fly ash micro-beads in cementitious material system," Construction and Building Materials, vol. 52, pp. 422-427, 2014.

[30] J. J. Chen, P. L. Ng, L. Gu, L. I. Albert, and K. H. Kwan, "Effects of fly ash microsphere on flowability and cohesiveness of cement paste," in Proceedings of the 2016 International Conference on Material Science and Engineering, Tokyo, Japan, 2016.

[31] H. Li, M. L. Cao, W. Zhang, J. Zhao, and S. X. Ding, "Study on high-strength concrete with large charge ultra-fine fly ash," Bulletin of the Chinese Ceramic Society, vol. 33, no. 5, pp. 10281034, 2014. 
[32] K. F. Tan and D. Y. Chen, "Effects of fineness, particle appearance and adding amounts of fly ash on cement and concrete properties," Building Energy Efficiency, vol. 4, pp. 27-28, 1998.

[33] A. K. H. Kwan and J. J. Chen, "Adding fly ash microsphere to improve packing density, flowability and strength of cement paste," Powder Technology, vol. 234, pp. 19-25, 2013.

[34] M. Cong and C. Bing, "Properties of a foamed concrete with soil as filler," Construction and Building Materials, vol. 76, pp. 61-69, 2015.

[35] Y. Kikuchi, T. Nagatome, T.-A. Mizutani, and H. Yoshino, “The effect of air foam inclusion on the permeability and absorption properties of light weight soil," Soils and Foundations, vol. 51, no. 1, pp. 151-165, 2011.

[36] S. Saride, A. J. Puppala, R. Williammee, and S. K. Sirigiripet, "Use of lightweight ECS as a fill material to control approach embankment settlements," Journal of Materials in Civil Engineering, vol. 22, no. 6, Article ID 003006QMT, pp. 607-617, 2010.

[37] T.-H. Kim, T.-H. Kim, and G.-C. Kang, "Performance evaluation of road embankment constructed using lightweight soils on an unimproved soft soil layer," Engineering Geology, vol. 160, no. 13, pp. 34-43, 2013.

[38] T.-S. Hou, "Influence law of characteristic water content on basic properties of light weight soil," Rock and Soil Mechanics, vol. 33, no. 9, pp. 2581-2587, 2012. 

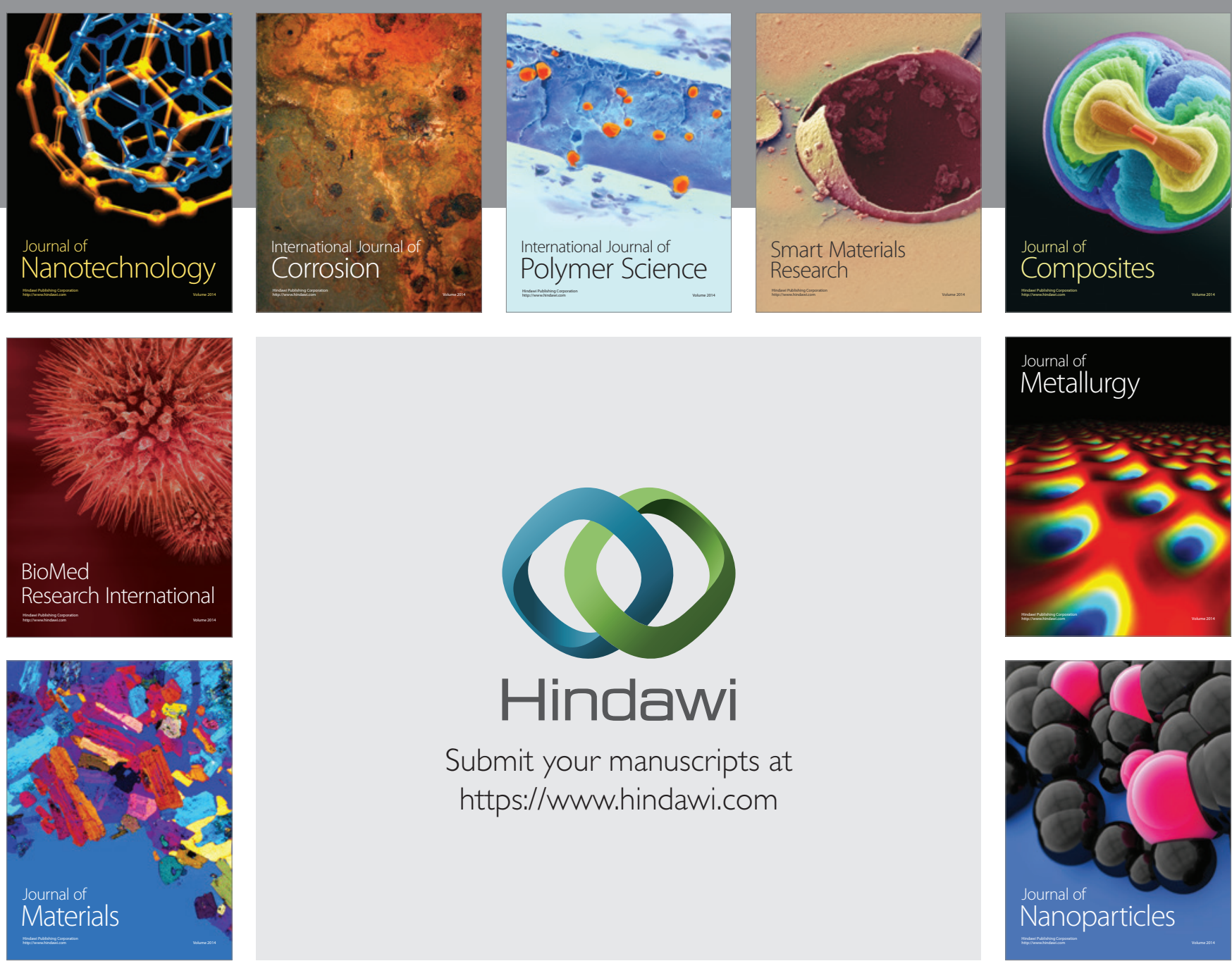

\section{Hindawi}

Submit your manuscripts at

https://www.hindawi.com

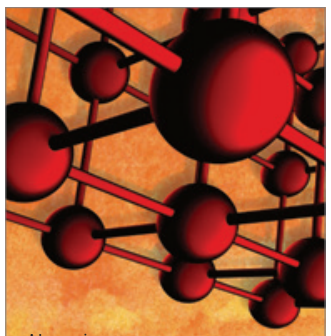

Materials Science and Engineering
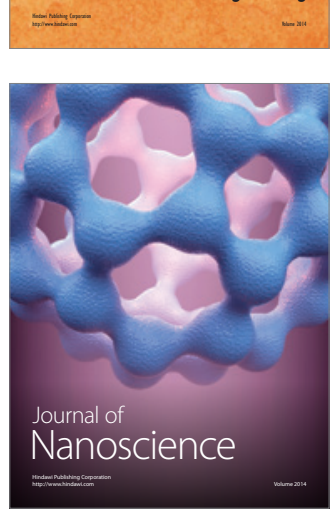
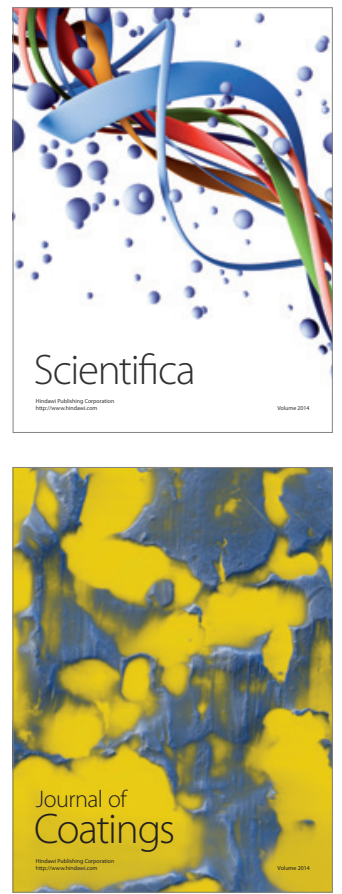
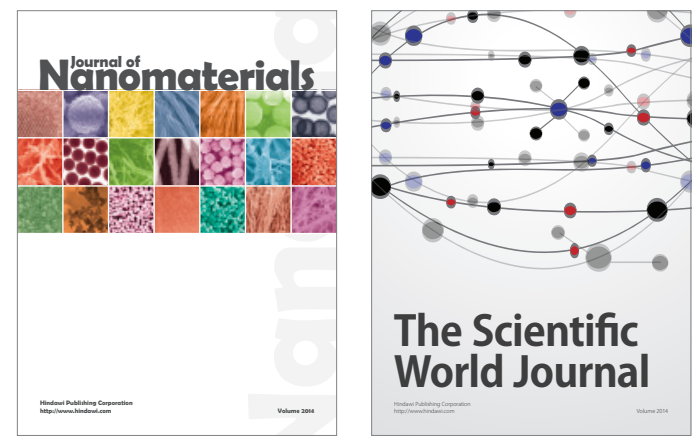

The Scientific World Journal
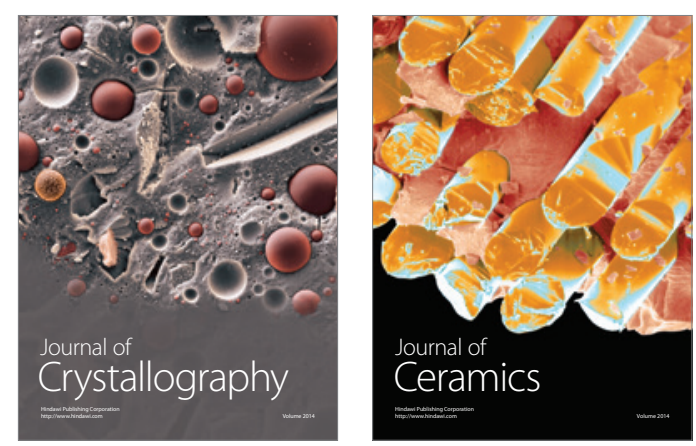
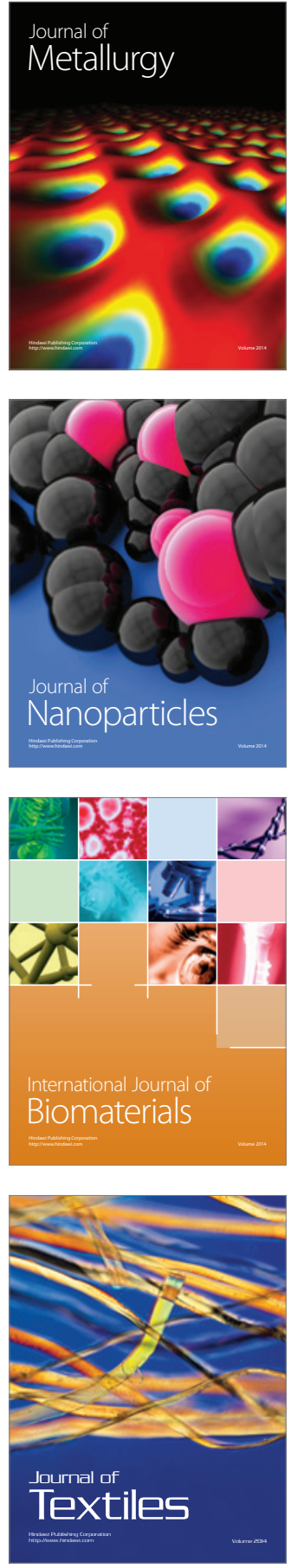